ESTUDOS LITERÁRIOS 


\section{OSKAR MARIA GRAF: ODISSÉIA DE UM SOLITÁRIO*}

Irene Aron**

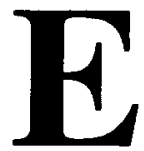

m 1997, comemorou-se o $30 .^{\circ}$ aniversário da morte de Oskar Maria Graf, um escritor que praticamente caiu no esquecimento. Nesse ano, o Instituto Goethe montou, em São Paulo, uma exposição itinerante sobre Graf que vem viajando pelo mundo desde o centenário de nascimento do autor. Tratou-se de uma iniciativa louvável justamente pela tentativa de, através da exposição, despertar novamente o interesse por Graf ao resgatar sua obra; divulgá-la entre nós é mais importante ainda, uma vez que Graf é praticamente desconhecido no Brasil. Este artigo pretende (re)apresentá-lo aos estudiosos da literatura alemã entre nós, mostrando aspectos de sua trajetória que, sem dúvida, demonstram seu papel de destaque dentro do contexto em que viveu e escreveu sua obra.

Oskar Graf nasceu em 1894, numa pequena localidade de nome Berg, junto ao lago de Starnberg, não muito longe de Munique. O pai, um humilde mestre padeiro, não oriundo da região, casa-se ali com a filha de camponeses locais, cuja origem, conforme o relato de Graf em escritos autobiográficos, remonta à Guerra dos Trinta Anos. É essa constelação que caracteriza a maior

* O artigo em questão foi adaptado de uma palestra proferida no Instituto Goethe de São Paulo, por ocasião da inauguração de uma exposição itinerante sobre o autor em comemoração ao centenário de seu nascimento e aos trinta anos de sua morte, sob o título "Oskar Maria Graf: odisséia de um solitário", mantido pela autora.

** Universidade de São Paulo 
parte da obra do autor e se mostraria muito fecunda como pano de fundo de suas narrativas, tornando-o uma espécie de representante da gente simples da província.

A partida para Munique aos quinze anos representa, de certa forma, uma fuga à tirania do irmão Max, à testa da padaria familiar, depois da morte do pai e, ao mesmo tempo, a libertação de um destino preestabelecido, qual seja, o de permanecer na pequena localidade e ajudar a tocar o negócio da família. Ao mesmo tempo, a cidade grande e cosmopolita determina a formação autodidata do escritor, que ali faz um pouco de tudo para contornar a situação de extrema penúria que o acomete. Essas atividades muito díspares e, por vezes, conflitantes entre si deram ensejo mais tarde à dificuldade de estabelecer um rótulo que se adaptasse perfeitamente a Graf, motivo também para que se visse nele uma certa falta de coerência.

Liga-se em Munique a grupos boêmios: suas festas que reuniam artistas e intelectuais em geral foram tanto aplaudidas quanto criticadas. Como uma espécie de bobo da corte, descobre nessa época sua capacidade de contar histórias para animar os convidados, usando o dialeto bávaro que seria sua marca registrada. Ao lado disso, através do encontro ocasional com o grupo anarquista Tat (Ação), entra em contato com a literatura anarquista e socialista e, por esse lado, dá-se sua formação política um pouco mais consistente, dentro da desorientação geral, oriunda, talvez, da ingenuidade e do deslumbramento do jovem Graf nessa fase.

Convocado a servir o exército na $1 .^{\text {a }}$ Guerra Mundial, foge à convocação de combater na frente russa, alegando doença mental, o que lhe valeu uma internação num hospital psiquiátrico por alguns meses. Alia-se, depois da guerra, a grupos que visam aproveitar-se da situação caótica reinante para auferir lucros fáceis, o que lhe valeu durante muito tempo a pecha de aproveitador e oportunista. Essa pecha pode até ser justificada quando se toma conhecimento de que Graf, nos anos 20, emprestou seu nome e seus contos a uma marca de charutos, em troca de boa remuneração. Antes disso, no fim da guerra, um outro episódio comprova o mesmo: um pintor de nome Oskar Graf, especializado em quadros heróicos e grandiosos, que gozava de certa fama na época, ofereceu ao escritor 500 marcos para que este mudasse de nome, e daí surgiu o "Maria", em seguida ao "Oskar".

Ao lado disso, como mais um exemplo da geléia geral que predominava na época, participa da formação da República de Conselhos bávara, uma forma de governo calcada em princípios soviéticos, de duração efêmera, da qual sobrou para Graf algum tempo na cadeia. Apesar das contradições, o envolvimento político de Graf, que ele define como de esquerda, não se resume aos anos entre 
as duas grandes guerras, mas manteve-se, transformado a partir de 1933 em luta contra o nacional-socialismo e, depois de 1945, como atividade antimilitarista, pela paz em plena guerra fria.

Paralelamente à formação política e, da mesma forma e num certo sentido multifacetada, Graf consegue em Munique, também a duras penas, realizar o grande sonho da infância, o de tornar-se escritor. As primeiras incursões pela literatura foram marcadas, igualmente, pela heterogeneidade. Em 1917, faz sua estréia literária como poeta expressionista, ligado ao movimento de vanguarda em voga na época, misturando de maneira confusa cristianismo com crítica social e pacifismo, e assim por diante. Ao lado disso, escreve textos ensaísticos a respeito de artistas ligados a ele e, também, textos ficcionais em prosa cujo espectro vai de histórias de índios a contos proletários, de sátiras a respeito da vida camponesa, histórias da província, histórias de almanaque, contos de fadas, contos camponeses eróticos do Bayrisches Dekameron (Decameron bávaro) de 1927 , até contos autobiográficos. Este seria o filão mais frutífero e constante da obra de Graf, de fato sua especialidade, conforme a frase irônica em seu cartão de visita: "O. M. Graf, escritor de província, especialidade: assuntos campestres". Nesse contexto, somam-se vários títulos, entre os quais, por exemplo, a narrativa autobiográfica Frühzeit (Primórdios), em que relata dados autobiográficos de 1907 a 1917, e sua continuação, Wir sind Gefangene (Somos prisioneiros), de 1927, em que um Graf mais amadurecido amalgama dados autênticos e ficcionais num escrito autobiográfico considerado um documento político contra a violência e o terror. A obra torna-se um sucesso de público e de crítica, com uma referência favorável até de Thomas Mann num jornal americano; mesmo fora da Alemanha, o romance consegue boa repercussão.

Até 1933, já haviam sido publicadas 24 obras de Graf, algumas de grande sucesso, de público e de crítica. Além das já citadas, são também dignas de menção as seguintes: Die Traumdeuter (Os interpretadores de sonhos), de 1924, Die Chronik von Flechting (A crônica de Flechting), de 1925, Die Heimsuchung (A aflição), de 1925, Bolwieser, de 1931, Einer gegen alle (Um contra todos), de 1932, Der harte Handel (A dura transação), de 1932.

A tomada do poder por Hitler marca uma nova fase na vida do autor. Se antes sua atuação política e sua criação literária pecavam, de certa forma, pela falta de coerência, um fato determina o destino de Graf a partir de 10 de maio de 1933. Graf já estava em Viena desde o dia 12 de fevereiro, data que marca, portanto, sua despedida - casual que seja - da Alemanha e o início de sua vida no exílio, e lá toma conhecimento da queima de livros de autores judeus ou contrários à ideologia vigente, organizada pelo regime nazista, e do fato de ter sido poupado. Vê-se na obrigação de praticamente solicitar a queima de sua obra 
e publica um protesto no jornal Wiener Arbeiterzeitung, em 12 de maio de 1933, sob o título "Me queimem!", que imediatamente é reproduzido em muitos jornais da imprensa internacional. Ali escreve Graf: "Estou na lista branca dos autores da nova Alemanha e todos os meus livros, à exceção de minha obra principal Wir sind Gefangene (Somos prisioneiros), foram poupados! Com isso, fui conclamado a ser um dos expoentes do 'novo' espírito alemão! Não mereci esta desonra! Com relação a toda minha vida e toda minha obra, tenho o direito de exigir que meus livros sejam lançados à chama pura da fogueira e não venham parar nas mãos sangrentas e nos cérebros podres dos bandos assassinos marrons." Em 1. ${ }^{\circ}$ de junho de 1933, vem a resposta cínica do regime, publicada no jornal Bayerische Hochschulzeitung: "Consideramos os livros de Oskar Maria Graf até agora, à exceção de certas tendências comunistas de salão e obscenidades grosseiras, como insignificantes demais para que fossem colocados na lista negra. Mas se o senhor poeta faz questão, não somos assim, estamos costumados a levar em consideração prazerosamente solicitações pessoais neste caso. Portanto, para o fogo com ele." Segundo Graf, seus livros foram então queimados a posteriori com a participação de estudantes e professores da Universidade de Munique, numa reunião especial. Logo em seguida, foi-lhe cassada a cidadania alemã.

Depois de breve estada na Áustria, em 1934, Graf participa do $1 .^{\circ}$ Congresso Pansoviético de Escritores, em Moscou, vive na Checoslováquia durante alguns anos; em 1938, aporta em Nova York. Durante 20 anos não sairia praticamente da cidade e, portanto, do país. Passou-se muito tempo, portanto, para que trocasse o status de exilado pelo de emigrante, pois hesitou muito em requerer a cidadania americana; depois da guerra, não visitou a Alemanha, temendo não poder retornar aos Estados Unidos pelo fato de ser apátrida. A não ser umas poucas palavras em inglês, Graf falava exclusivamente alemão, e sempre com o característico forte sotaque bávaro. Graf recusou-se a tornar-se cidadão americano, devido ao seu parco inglês e por ter que repetir certas frases do juramento que o compeliam, segundo ele, a pegar em armas para defender a nova pátria, caso necessário. Somente em 1958 foi-lhe feita a concessão especial de omitir as tais frases e, assim, com o passaporte americano, Graf fez quatro viagens à Alemanha, entre 1958 e 1965; nunca tomou, porém, a decisão de voltar definitivamente a Munique. A grave doença que o acometeu, impediu-o depois de qualquer iniciativa a esse respeito e, em 1967, aos 73 anos, morreu de câncer em Nova York.

Desde a sua chegada aos Estados Unidos, Graf tornou-se uma das personalidades mais conhecidas entre os exilados vindos do $3 .^{\circ}$ Reich. Seu famoso protesto tinha sido publicado em inúmeros jornais estrangeiros e até o 
New York Times havia dado uma notícia a respeito. As publicações de obras escritas durante os primeiros anos de exílio na Áustria e na Checoslováquia - e aí devem ser citados, principalmente, o romance Anton Sittinger, de 1937, e o romance antifascista Der Abgrund ( $O$ abismo), de 1938 - e sua colaboração em revistas literárias importantes publicadas no exílio tinham tornado Graf bastante conhecido entre seus colegas escritores. Daí o fato de ter assumido uma posição importante entre os muitos intelectuais alemães nos Estados Unidos, tornandose logo presidente da GAWA, a German-American Writers Association (Associação Americana de Escritores Alemães), que promovia a divulgação de obras escritas no exílio e o auxílio financeiro a intelectuais necessitados.

Durante os primeiros anos no exílio, Graf continuou a relatar em seus livros as histórias da província bávara, detendo-se na focalização de detalhes e reminiscências da saga familiar. Das Leben meiner Mutter ( $A$ vida de minha $m a \tilde{e})$, um romance biográfico iniciado ainda na Checoslováquia e terminado entre 1939 e 1949 nos Estados Unidos, descreve a vida de seus antepassados através da figura forte de sua mãe. Alguns volumes de contos autobiográficos ainda exploram o mesmo veio, pois, apesar da distância temporal e geográfica, Graf ainda mantinha viva em si a lembrança marcante de sua origem.

No entanto, obviamente, com o decorrer do tempo, as imagens da pátria bávara começariam a se dissipar e, a exemplo do que ocorreu com outros escritores alemães no exílio, deram lugar à visão de um futuro idealizado, chamando a atenção para os perigos de uma nova guerra, para o crescente militarismo do pós-guerra, para a ameaça de destruição total depois do lançamento das bombas atômicas sobre Hiroshima e Nagasaki, conclamando para a responsibilidade do intelectual e, como consequiência, para uma tomada de uma posição ética diante dos problemas políticos e sociais de nosso tempo. É esse o tema do romance Die Erben des Untergangs: der Roman einer Zukunft (Os herdeiros da queda: romance de um futuro), publicado a princípio com o título Die Eroberung der Welt (A conquista do mundo), em 1949.

Graf assume nessa fase uma postura responsável e madura. Alguns críticos consideraram o período do exílio como o mais frutífero de Graf, acompanhando um desenvolvimento paralelo de autor e obra, ou seja, à medida que Graf passa por um processo de maior reflexão e amadurecimento como ser humano e, portanto, como escritor, também sua obra espelha essa consistência. Conforme dito, Graf recusava-se também a voltar à pátria em ruínas como alguém que busca vingança ou perdão ou como colaborador beneficente e, no decorrer do tempo, passa a considerar-se não mais como um exilado, mas como um emigrante, participando de atividades culturais nos Estados Unidos. 
Através dessa atitude, a questão da responsabilidade do intelectual alemão face à catástrofe da Alemanha ocupa uma posição de destaque em suas reflexões. Chega à convicção de que o fracasso da democracia na Alemanha deveu-se também e em grande parte à culpa dos intelectuais que, como ele, de certa forma mantiveram-se comodamente em suas torres de marfim, à margem dos acontecimentos, deixando que estes seguissem seu curso sem qualquer interferência por parte deles, não se eximindo da própria culpa. Assim pronuncia-se num discurso escrito entre 1945 e 1947: "Com maestria, elaborávamos romances e poesias, nos quais temerosamente evitava-se chamar a atenção para os perigos ameaçadores e tomar posição contra a barbárie iminente." Um outro trecho consiste numa espécie de mea culpa: "A maioria de meus livros tratam apenas do povo alemão e não eram políticos. Caberiam como uma luva para os nazistas, pois [...] eles não tinham nenhum poeta verdadeiramente popular." Tais reflexões, sem dúvida, encontram respaldo nas afirmações de especialistas, segundo as quais o expressionismo devido à sua confusão ideológica continha em si potencialmente o nascedouro das duas correntes políticas, tanto do fascismo quanto do socialismo, e nesse contexto que recua até o começo do século situam-se muitos intelectuais alemães, inclusive Graf.

Sua atitude crítica não era tão comum entre os intelectuais alemães no exílio, à exceção, talvez, de alguns nomes como Hermann Broch ou Klaus Mann. Graf via seu exílio sem nenhuma mágoa e até o considerava a causa de ter se tornado um ser humano mais consciente e responsável. Apesar de sua atitude crítica colocá-lo numa posição de isolamento, era nos outros intelectuais que Graf via a terrível solidão a que estavam condenados como conseqüência, segundo Graf, de uma certa arrogância e orgulho nacional não confessados que os impedia de elaborar ou mesmo aceitar sem preconceitos o novo e o estranho da pátria adotiva. Graf descreveu esta problemática na obra Die Flucht ins Mittelmäßige: ein New York Roman (A fuga para a mediocridade: um romance nova-iorquino), de 1959.

Nesses anos de esquecimento, depois de sua morte, algumas obras de Graf foram transpostas para o cinema ou para a televisão, como Bolwieser (Fassbinder, 1977), Anton Sittinger e Unruhe um einen Friedfertigen (Desassossego de um pacifista), este último com um roteiro adaptado por Martin Sperr. Não consta, porém, que a recepção de Graf tenha sido marcada por um novo alento.

Aos olhos de um leitor de hoje, muitos dos textos de Graf, escritos a partir do exílio, quando sua consciência política foi aguçada pelos acontecimentos na Alemanha, são documentos de época de grande importância. No romance $D e r$ Abgrund ( $O$ abismo), por exemplo, os fatos históricos são entrelaçados numa 
história fictícia de personagens que vivenciam, a exemplo de Graf, a derrocada da República de Weimar e sua capitulação frente aos nazistas, e também a conseqüente série de acontecimentos na Áustria. No entanto, apesar do interesse histórico que possa despertar esse relato preciso dos acontecimentos, no exemplo citado, chama a atenção, muitas vezes, a fragilidade da textura, já que as inúmeras descrições de episódios históricos e de personagens verídicos e ficcionais nem sempre são entretecidas apropriadamente, de maneira que o todo parece desmoronar.

Por outro lado, se algumas vezes o autor deixa escapar, em alguns casos, a falta de um grande fôlego literário, as histórias autobiográficas ou biográficas, as histórias da província constituem, com certeza, para o leitor de hoje, uma (re)descoberta proveitosa e prazerosa. A habilidade de contar histórias, ainda nos primeiros tempos em Munique, mantém-se quando Graf passa-as para o papel, revelando sua técnica magistral de transpor a linguagem plástica c sonora da oralidade para o texto literário, utilizando, para tanto, o dialeto bávaro como um meio literário de grande efeito. $O$ próprio autor reitera esse fato, quando afirma: "Narrar, sem dúvida, é algo basicamente social e comunicativo, que aproxima mais as pessoas - pelo menos enquanto estão ouvindo. Um leitor, ao contrário, precisa da solidāo."

O fato de retratar a gente simples das aldeias da Alta Baviera, com sua cor local, com sua ironia e humor típicos, não faz desses textos exemplos de literatura trivial ou de segunda categoria, conforme algumas críticas a Graf antes de 1933. Na verdade, embora seu cenário seja a província bávara, o autor consegue ultrapassar esse microcosmo em suas histórias, focalizando nelas problemas inerentes ao ser humano em qualquer lugar $\mathrm{e} \mathrm{em} \mathrm{qualquer} \mathrm{tempo.} O$ próprio autor confirma isso ao afirmar: "Também uma província ou uma aldeia são, no fundo, uma imagem reduzida do mundo maior." Embora primem pela simplicidade, refletindo a aversão do autor pelo intelectualismo arrogante, motivada pela origem simples e formação nāo convencional, as narrativas de Graf não celebram o idílio da vida campestre. Não se encontram ali pássaros que gorjeiam ou rios de águas cantantes. Ao contrário, sua "província" é cheia de conflitos e contradições, é descrita com a perspectiva crítica daquele filho da terra que se tornou intelectual de esquerda. O povo simples e humilde não é transformado em herói, tanto pode ser mostrado por scu lado limitado e egoísta, quanto pelo lado prestativo, trabalhador ou sem expectativa, embora Graf não torne suas narrativas um libelo a favor da luta de classes. Graf evita em suas narrativas mais originais a apresentação de personagens sutis ou psicológicos: os personagens simples que descreve apresentam-se a si mesmos, não através da técnica do monólogo interior, pois isso seria artificial e elaborado demais para 
Graf, e sim através do diálogo, da ação e da descrição de sua função social. Isso tudo numa linguagem caracterizada por frases curtas, pela seqüência assindética de verbos, pela utilização de metáforas e símiles, e, principalmente, pela utilização do dialeto bávaro. Esta barreira, facilmente transponível no decorrer da leitura, não deveria, portanto, assustar o leitor, em particular o leitor brasileiro. Os romances autobiográficos, como Die Chronik von Flechting (A crônica de Flechting), e os contos, dentre os quais os disponíveis estão contidos no volume Auffassung freibleibend (Concepção livre), merecem ser lidos para que se possa sentir, através deles, um pouco do sabor mais característico de Oskar Maria Graf e perceber que, apesar do tempo transcorrido, a vida e os personagens da aldeia bávara permanecem intactos em sua simplicidade e em sua grande humanidade.

Por fim, faz-se necessário retomar a questão do título dado à exposição itinerante e, por conseguinte, a este texto: Odisséia de um solitário. Sem dúvida, Graf, nos anos entre as duas guerras, pode ter sofrido a solidão do discriminado, por escrever uma literatura dita popular e considerada, por isso, muitas vezes, de segunda categoria. Graf, por certo, numa tentativa de provocar os intelectuais ditos empinados, contribuiu de propósito para que esta acepção se firmasse, como no caso citado do cartão de visitas, ou quando, propositadamente, apresentava-se vestido de calção de couro e chapéu à moda bávara. Mas a literatura disponível no Brasil a respeito do autor parece confirmar a impressão de que Graf não estava nem um pouco preocupado com tudo isso. Talvez cause estranheza a afirmação de que, em primeiro lugar, não fosse seu protesto antinazista, um tanto panfletário, provavelmente Graf tivesse caído mais cedo no esquecimento e, em segundo lugar, de que justamente o exílio tornou Graf um nome de maior prestígio. Durante essa fase, não parece que Graf tenha sido mais solitário que outros tantos escritores que compartilharam do mesmo destino, nem que sua "odisséia" tenha sido particularmente mais cheia de vicissitudes, pois o termo odisséia remete a uma "viagem" permeada de percalços e obstáculos. Ao contrário, sua atividade no exílio e através dela o seu empenho em desvencilhar a imagem do nazismo da imagem da Alemanha, de seus intelectuais e de sua cultura, e tentar diminuir o ódio provocado por esta imagem, fazem crer que ele não ficou recluso, pelo contrário, saiu à luta e cumpriu com dignidade o papel que se impôs.

1 ARNOLD, Heinz Ludwig. Oskar Maria Graf, Text + Kritik. München: Sonderband, 1986. 


\section{RESUMO}

O artigo pretende apresentar o escritor alemão Oskar Maria Graf aos estudiosos da literatura alemã no Brasil. Graf, autor principalmente de obras de cunho popular e regional, teve grande sucesso na Alemanha até o seu exílio forçado pelo Terceiro Reich. Passou a viver nos Estados Unidos, retornando à Alemanha após a Segunda Guerra Mundial apenas para divulgar sua obra através de leituras e conferências. Seus romances e contos, praticamente desconhecidos no Brasil, retratam a vida nas aldeias natais da Baviera. O colorido local desses textos é salientado através da utilização do dialeto bávaro pelo autor.

Palavras-chave: literatura alemã contemporânea, literatura popular e regional, literatura e exilio.

\section{ZUSAMMENFASSUNG}

Der Artikel versucht, dem brasilianischen Germanistikstudenten den deutschen Schriftsteller Oskar Maria Graf vorzustellen. Graf, hauptsächlich als Volks- und Heimatdichter bekannt, genoss in Deutschland einen ziemlich grossen Erfolg, bis das Dritte Reich ihn zum Exil erzwang. Seitdem lebte er in den USA und nach dem Krieg kam er zu Besuch nach Deutschland, lediglich um sein Werk durch Lesungen und Vorträge bekannt (er) zu machen. Seine Romane und Erzählungen, die in Brasilien völlig unbekannt sind, spiegeln das Leben in den Dörfern seiner Heimat, Bayern, wider. Der Lokalkolorit wird durch den Gebrauch des Bayrischen Dialekts stark unterstrichen.

Schlüsselwörter: Zeitgenössische Deutsche Literatur, Volks- und Heimatliteratur, Literatur und Exil. 